\title{
Roles of hydrodynamics and larval behaviour in determining spatial aggregation in the tunicate Ciona intestinalis
}

\author{
Jon N. Havenhand*, Ib Svane \\ Royal Swedish Academy of Sciences, Kristineberg Marine Biological Station, S-450 34 Fiskebäckskil, Sweden
}

\begin{abstract}
Much attention has been paid in the literature to the importance of gregariousness of marine invertebrate larvae and its potential role in the formation of aggregated assemblages in the field. In the waters of the Swedish west coast Ciona intestinalis L. can be highly aggregated. Laboratory experiments showed that larvae of $C$. intestinalis were not stimulated to settle and metamorphose in aqueous extracts of adult tunic, nor were settlement patterns on uniform, plane substrata aggregated. Field experiments with adult $C$. intestinalis and adult $C$. intestinalis mimics indicated that recruitment was dependent on the number of adults or mimics present (higher numbers yielded higher settlement). However, recruitment density around a given number of $C$. intestinalis was not significantly different from that around the same number of mimics. These results indicate that formation of aggregations of C. intestinalis in the field are probably the result of hydrodynamic processes rather than gregarious larval settlement. This result is in contrast to those obtained from similar investigations of other ascidian species.
\end{abstract}

\section{INTRODUCTION}

The ability of marine invertebrate larvae to respond to a variety of environmental cues at the time of settlement has been recognised for a long time. In many cases, behavioural responses of the settling larva to the presence of established conspecific adults have been shown to play a central role in larval site selection (e.g. Knight Jones 1953, Crisp 1974, Highsmith 1982, McGee \& Targett 1989). Whilst much of this work has been conducted in vitro and its applicability to field situations has rightly been questioned (Moore 1975, Butman 1987, Pawlik in press), such processes are of relevance to the recent increase in interest in the importance of larval settlement and recruitment to community dynamics (Underwood \& Denley 1984, Keough \& Chernoff 1987, Menge \& Sutherland 1987, Roughgarden et al. 1988).

Gregariousness - defined here as the process by which competent larvae are stimulated to settle in a given location by the presence of conspecific individu-

- Present address: Friday Harbor Laboratories, University of Washington, 620 University Road, Friday Harbor, Washington 98250 , USA als (other larvae, post-metamorphs or established adults) - has been demonstrated in many phyla of marine invertebrate (reviewed by Burke 1986). Ascidian larvae can show pronounced settlement preferences (e.g. Svane 1987), and strong gregarious responses to conspecifics, and 'associative' responses to heterospecifics (Crisp 1974) have been documented (Young \& Braithwaite 1980, Svane et al. 1987, Young 1988, see Svane \& Young 1989 for review). In some cases such responses have been judged to be sufficiently strong to explain the observed patterns of aggregation encountered in the field (Havenhand \& Svane 1989).

The solitary ascidian Ciona intestinalis $\mathrm{L}$. is found throughout most temperate regions of the world (Millar 1953). In Scandinavia, fjord populations of $C$. intestinalis can be very dense with up to several thousand individuals per square meter (Svane 1983). In shallow waters only a single generation is produced at any one time (usually annually although sub-annual cycles may occur; Dybern 1965). Deeper populations, however, show overlap of generations (Svane \& Young 1989 and references therein).

In Gullmarsfjorden, western Sweden, deep-water populations ( $>15 \mathrm{~m}$ depth) often comprise marked 
aggregations in which juvenile Ciona intestinalis can be found growing in close proximity to, and often on the cuticle of, older established individuals. Dybern (1965) has shown that in these populations C. intestinalis will not usually commence spawning until the average water temperature has risen above $\sim 8^{\circ} \mathrm{C}$ which, in Gullmarsfjorden, usually occurs in May and results in a peak of spawning activity. Other ascidian species in this area do not commence spawning until later in the year, and therefore the opportunity arises to conduct field experiments on $C$. intestinalis settlement without the complication of heterospecific settlement (and consequent interactions). This paper reports the results of an investigation to determine whether the observed aggregations of $C$. intestinalis could be the result of gregarious larval behaviour.

\section{MATERIALS AND METHODS}

Ciona intestinalis L. larvae were obtained by artificial fertilisation. Ova and sperm were removed separately from the gonoducts of freshly collected adults and placed in Petri dishes on a seawater table at near ambient temperatures $\left(13\right.$ to $\left.16^{\circ} \mathrm{C}\right)$. In order to permit expansion of the chorion, ova were mixed with seawater and allowed to stand for ca $30 \mathrm{~min}$ before diluted sperm suspension was added. In all cases, ova were cross-fertilised. After $1 \mathrm{~h}$ the sperm suspension was washed off by transferring the cultures to acrylic plastic culture vessels closed at the bottom with fine nylon mesh and held in flowing seawater. Embryonic and larval cultures were maintained in such culture vessels until ready for use.

Tissue extract experiments. Tissue extracts were prepared from individuals which had been freshly collected by SCUBA diving. Tunic (only), body tissues (i.e. no tunic) or whole specimens were homogenised in seawater at an initial concentration of $0.5 \mathrm{~g}$ tissue (wet wt) $\mathrm{ml}^{-1}$ seawater. The resulting homogenates were centrifuged at $14000 \times g$ for $30 \mathrm{~min}$. Supernatants were then decanted, cleared through a $0.45 \mu \mathrm{m}$ membrane filter and stored in a refrigerator until use. All extracts were used within $24 \mathrm{~h}$ of preparation.

Tissue extracts of 'whole', 'body' and 'tunic' were tested at $5 \%$ concentrations. Unfiltered seawater served as a control treatment. Four replicates of each treatment were used. As some ascidian larvae are stimulated to settle and metamorphose rapidly in new, clean plastic Petri dishes (authors' unpubl. data on Ascidia mentula), treatments were contained in $9 \mathrm{~cm}$ diameter Petri dishes which had been 'conditioned' prior to the experiment by being allowed to stand in running seawater for $24 \mathrm{~h}$. Initial experiments indicated that ca $50 \%$ of larvae kept in filtered seawater metamorphosed after ca $18 \mathrm{~h}$, but that this period varied considerably. Therefore, an additional 'control' treatment was observed periodically in order to ascertain the time at which $50 \%$ of larvae had metamorphosed.

Approximately 50 newly hatched larvae were pipetted into each treatment. Petri dishes were maintained at ambient temperature $\left(15\right.$ to $\left.16^{\circ} \mathrm{C}\right)$ on a seawater table in constant light. On the basis of periodic observations of the extra control treatment, the number of larvae and metamorphs was determined after $16 \mathrm{~h}$.

Spatial distribution at settlement. Newly hatched, swimming larvae (obtained from multiple cross-fertilisations) were transferred to 12 clean glass Petri dishes containing fresh seawater. As Ciona intestinalis larvae will preferentially settle on the undersides of surfaces (Yamaguchi 1975), clean plastic Petri dishes were floated on the surface of these dishes to facilitate settlement. Dishes were incubated in the dark on a seawater table at ambient temperatures. After $3 \mathrm{~d}$, the floating 'lids' were carefully removed and the pattern of settlement was enlarged and sketched with the aid of an overhead projector. Spatial distribution of settlement patterns was analysed using nearest-neighbour techniques (Clark \& Evans 1954, Diggle 1979).

Recruitment around adults in the field. A field experiment was conducted to determine whether adult Ciona intestinalis influence the density of recruitment around them. Recruitment was quantified around both adult $C$. intestinalis and $C$. intestinalis mimics (polyethylene tubing of equivalent dimensions). Five treatments were employed, each with 4 replicates: none (empty), 1 or $5 \mathrm{C}$. intestinalis and 1 or 5 mimics, attached to $16 \times 16 \mathrm{~cm}$ square acrylic plastic panels which had been sprayed with matt black enamel paint. Prior to the experiment, panels had been conditioned in running seawater for more than $2 \mathrm{wk}$, after which they had been scrubbed clean in seawater prior to use. Panels were arranged 50 $\mathrm{cm}$ apart in a flat $4 \times 5$ array. This array was attached to a vertical rock wall at 20 to $25 \mathrm{~m}$ depth at Gåsklåvan, Gullmarsfjorden, western Sweden (Site 2 in Svane 1988), so that the panels hung vertically mimicking the natural substratum. Any $C$. intestinalis on the rock wall which were close to or within the area occupied by the panel array were removed at this time.

After placement of the panel array, SCUBA divers attached 1 or clusters of 5 Ciona intestinalis or mimics to nylon bolts which were positioned in the centres of all panels. C. intestinalis clusters were held together by monofilament nylon line (ca $0.5 \mathrm{~mm}$ diam.) which was sewn through the tunic at the base of the individuals. Previous laboratory observations had shown that specimens treated in this way survived and grew for periods in excess of $3 \mathrm{mo}$. Plastic 'ratchet' tubing clamps (NOAX AB, Stockholm, Sweden) were passed through the monofilament nylon, loop and then used to attach 
clusters to the nylon panel bolts. Mimics and individual C. intestinalis were treated in an analogous manner. In all cases treatments were arranged so that the bases of the $C$. intestinalis or mimics were in close contact with the panel simulating adhesion to natural substrata. Treatments were attached to the panel array such that no columns or rows contained more than one replicate of any given treatment.

After $20 \mathrm{~d}$ the panels were carefully removed from the array (in situ), placed in covered water-filled containers and transported back to the laboratory for analysis. The number of larvae present in $4 \times 4 \mathrm{~cm}$ squares located $2 \mathrm{~cm}$ above, below, and to the right and left of the point of attachment of the treatment were determined with the aid of a stereo dissecting microscope. Larvae which had settled closer than $2 \mathrm{~cm}$ to the point of attachment were not included in the analysis due to the possibility of chance abrasion by the treatments. Post-settlement mortality which occurred during the 2 wk exposure period was not quantified.

\section{RESULTS}

Approximately $60 \%$ of artificially fertilised Ciona intestinalis ova developed and hatched normally. Hatching was usually observed after ca $27 \mathrm{~h}$ (at $15^{\circ} \mathrm{C}$ ) and continued over a period of 5 to $6 \mathrm{~h}$. In the absence of any other stimulus, the majority of $C$. intestinalis larvae settled (in the culture dishes) within $24 \mathrm{~h}$, although some larvae were observed swimming actively after as long as $5 \mathrm{~d}$.

\section{Tissue extract experiments}

The porportion of larvae which had metamorphosed after $16 \mathrm{~h}$ in each treatment is shown in Fig. 1. Arc-sine transformation of the data rendered them homoscedastic $\left(\mathrm{F}_{\max }\right.$-test, Sokal \& Rohlf 1981). One-way analysis of variance (ANOVA) of the effects of tissue type on

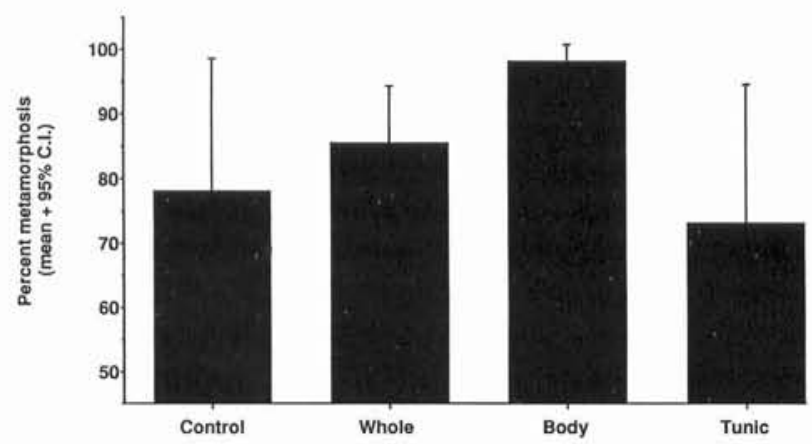

Fig. 1. Ciona intestinalis. Proportion of larvae which had metamorphosed after $16 \mathrm{~h}$ in response to aqueous extracts of adult tissues metamorphosis yielded a significant result $(\mathrm{F}=9.24, \mathrm{p}$ $=0.002$ ). The proportion of larvae metamorphosing in the 'body' tissue extract was significantly greater than that in the other treatments (Scheffé's F-test, $\mathrm{p}<0.05$ ).

\section{Spatial distribution at settlement}

Nearest-neighbour analysis indicated that in 10 out of the 12 replicates, settlement was not significantly different from random ( $p>0.05 ;$ Fig. 2). Two of the

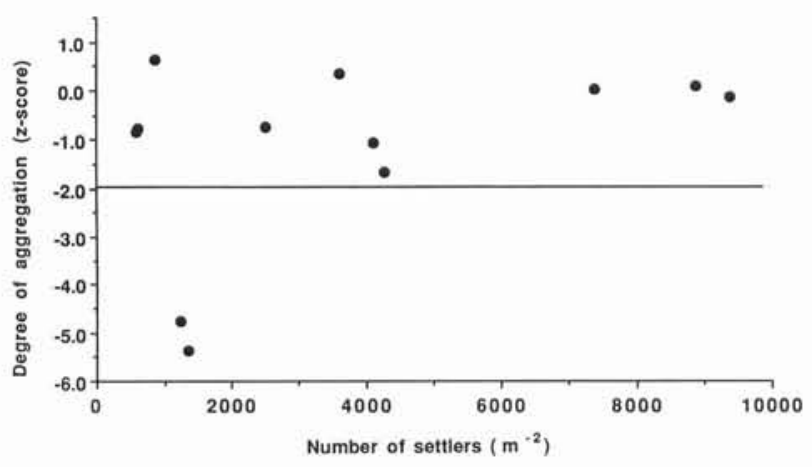

Fig. 2. Ciona intestinalis. Spatial distribution of newly settled larvae in Petri dishes. Z-values are from nearest-neighbour analysis and indicate statistical significance of the observed spatial pattern: $\mathrm{z}$-values greater than -1.96 (solid horizontal line) are not significantly different from random. Values less

than this are significantly non-random and aggregated

replicates did show non-random (aggregated) settlement, however at this probability level, the chance of obtaining 2 such results out of 12 tests is not in itself statistically significant (binomial test, $\mathrm{p}=0.12$ ).

\section{Recruitment around adults in the field}

Mean recruitment density ranked in the order 5 mimics $>5$ Ciona intestinalis $>1$ C. intestinalis $>1$ mimic $>$ none (Fig. 3). Analysis of the numbers of $C$. intestinalis recruits at each position on each panel indicated that the variances were not heteroscedastic (Scheffé - Box test, $\mathrm{p}>0.05$ ). The 'none' data were excluded from initial analyses in order to obtain a balanced design, and a 3-way ANOVA with 'type' (real, or mimic), 'number' (1 or 5) and 'position' (up, down, left, or right) as main effects was conducted. This analysis yielded no significant interactions and indicated that recruitment density was independent of position. Therefore, data for each panel (all positions) were combined and the data set was re-analysed by 2-way ANOVA. This showed that 'number' had a significant effect on recruitment intensity, but both the 'type' main effect and the interaction were non-significant (Table 1). 


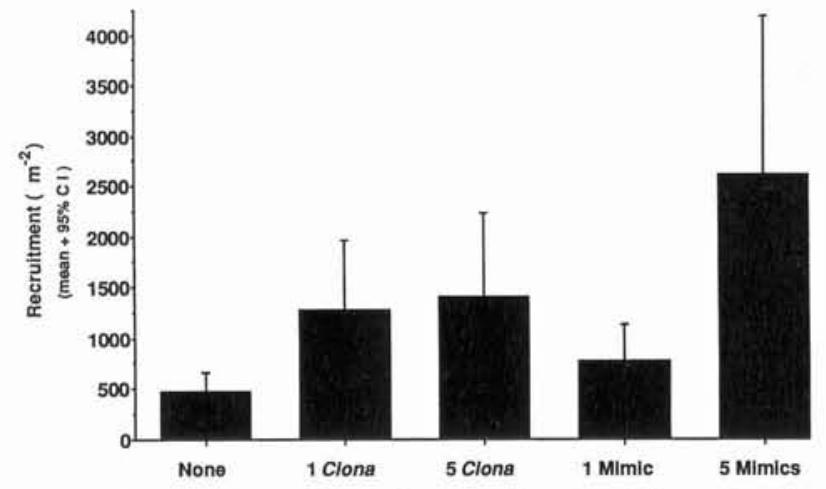

Fig. 3. Ciona intestinalis, Settlement density of larvae in the field around real and mimic adult $C$. intestinalis. Data are mean settlement density around the treatments on settlement panels ( 4 panels per treatment)

Table 1. Ciona intestinalis. Two-way ANOVA for observed densities of newly settled $C$. intestinalis around differing numbers ( 1 or 5 ) of adult $C$. intestinalis and adult $C$. intestinalis mimics

\begin{tabular}{|lccc|}
\hline Source & $\begin{array}{c}\text { Mean } \\
\text { square }\end{array}$ & F & p \\
\hline Type $(C$, intestinalis & 5.062 & 0.601 & 0.441 \\
or mimic) & 39.06 & 4.638 & 0.035 \\
Number (1 or 5) & 30.25 & 3.591 & 0.063 \\
Interaction & 8.423 & & \\
Error & & & \\
\hline
\end{tabular}

Since no significant effect of type was found in the 2way ANOVA, results from Ciona intestinalis and mimic treatments were combined in order to compare recruitment density around these treatments with that on the 'empty' plates. This yielded a significant result $(\mathrm{F}=$ 5.33, $\mathrm{p}=0.007$ ) in which recruitment around 5 individuals' was at significantly higher densities than on empty panels (Scheffé's F-test, $\mathrm{p}<0.05$ ) (Fig. 3).

\section{DISCUSSION}

The observation that tissue extracts had little or no effect on frequency of metamorphosis of Ciona intestinalis is perhaps surprising in view of the strong responses which have been reported from similar experiments on other ascidian species (Ascidia nigra, Polyandrocarpa sp., Grave \& Nicoll 1939; Ascidia mentula, Ascidiella scabra, Svane et al. 1987). Whilst a significantly higher proportion of larvae metamorphosed in 'body' tissue extract than in 'tunic', 'whole' and control treatments (Fig. 1), the ecological relevance of this response seems limited. In a series of experiments which employed the same experimental protocol as that used here, Svane et al. (1987) found that 'tunic' tissue extracts elicited significantly higher responses than 'body' extracts in both the species they studied. This raises the possibility that Ascidia spp. and Ascidiella spp. larvae may respond to the presence of adults (effectively adult tunics) in the field (see Havenhand \& Svane 1989). Apparently such processes do not operate in $C$. intestinalis.

Again, in contrast to earlier work on Ascidia mentula, the settlement patterns of Ciona intestinalis larvae in Petri dishes were not significantly aggregated. Moreover, the degree of settlement aggregation showed no noticeable trend with settling density (Fig. 2; cf. Havenhand \& Svane 1989, their Fig. 4).

Notwithstanding the possibility of laboratory artifacts, these results suggest that the observed aggregations of Ciona intestinalis in the field are probably the result of processes other than larval attraction to conspecifics at the time of settlement. This hypothesis is confirmed by the observed distribution of recently settled $C$. intestinalis around both adult $C$. intestinalis and mimics: recruitment density around $C$. intestinalis was not significantly different from that around mimics. However, irrespective of whether the 'ascidian' was real or not, the number of ascidians present had a significant effect on recruitment such that the highest densities were found around groups of individuals (Table 1, Fig. 3). Some degree of caution should be exercised when interpreting these data, as the results of a 1-way ANOVA on $C$. intestinalis data alone showed that settlement density did not vary with the number of $C$. intestinalis present (analysis not shown). Clearly, this indicates that variation in recruitment density was considerable. Nevertheless, this analysis had fewer degrees of freedom and, therefore, lower resolving power. With that caveat in mind, the results obtained here support the hypothesis that hydrodynamic factors operating at the time of settlement may be the primary determinant of immediate post-settlement distribution patterns.

For the purpose of simplified hydrodynamic modelling, a single adult Ciona intestinalis can be assumed to liken a vertical cylinder protruding from a plane substratum. At the flow velocities typically found around C. intestinalis at the experimental site $\left(2\right.$ to $5 \mathrm{~cm} \mathrm{~s}^{-1}$ at ca $10 \mathrm{~cm}$ away from the substratum, pers. obs.), such a 'roughness element' would influence downstream flow by the periodic shedding of vortices (Vogel 1981). Reduced water flow velocities would occur immediately in front of and behind the cylinder, however perhaps the most significant hydrodynamic effect with respect to settling larvae would be the production of a turbulent wake. This would introduce temporally and spatially heterogeneous shear stress at, or close to, the substratum behind the cylinder (Eckman 1983, Ertman \& Jumars 1988). Larval settlement in this region could 
be either augmented or reduced depending on the degree of shear, larval swimming abilities, and settlement preferences.

This pattern applies to situations in which the water striking the cylinder has laminar or smooth turbulent flow. However, currents passing the rock wall and settling panels were more turbulent. [This can be calculated from the roughness Reynolds number, $R_{,}=u . D / v$

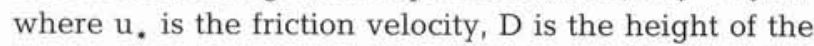
roughness elements and $v$ is the kinematic viscosity; Denny (1988). Re. was typically in the order of 60 at this site: a value which indicates that flow is transitional between smooth turbulent and fully rough turbulent; Ertman \& Jumars (1988)]. The distribution of shear stress around individual Ciona intestinalis or mimics under such conditions is less predictable than the example given above, however on a time-averaged basis the patterns outlined here should be applicable. Although high densities of roughness elements can lead to 'skimming flows' (e.g. Eckman et al. 1981, Eckman 1983), it is probable that the point-located aggregations of $5 \mathrm{C}$. intestinalis or mimics used here would act in the manner of large isolated roughness elements.

The measured water flows cited above are as much as an order of magnitude greater than the maximum swimming speed of Ciona intestinalis larvae $\left(4 \mathrm{~mm} \mathrm{~s}^{-1}\right.$; Berrill 1931). However, in the wake behind a protrusion (adult C. intestinalis for example) larvae may encounter zones of increased turbulence and variable velocity. Under such circumstances, larvae may only be able to settle in areas of reduced flow rate such as those found in turbulent wakes (even when flow conditions do permit larval settlement on open substrata, settlement would be greater in wake areas). Whether larval settlement in such wakes is a result of increased frequency of contact with the substratum, increased likelihood of effecting settlement in such areas, or a preference for variable shear environments is as yet unclear. Butman (1987) has emphasised that swimming abilities of many marine invertebrate larvae are so poor relative to ambient water currents that larvae may be advected and deposited at or near the substratum arbitrarily. The results shown here indicate that such hydrodynamic processes are important in determining post-settlement distribution patterns.

Whilst a hypothesis to explain larval settlement around adults can be erected, aggregations of Ciona intestinalis adherent to the surface of solitary established adults cannot be explained so readily by such mechanisms. The results obtained suggest that such aggregations are not the result of adult-larval attractiona conclusion corroborated by the occasional observation of similar clusters adherent to the tubes of the polychaete worm Sabella pavonina Savigny. Several alternative (not mutually exclusive) explanations can be put forward; firstly it is possible than $C$. intestinalis larvae may settle on protruding surfaces as a result of chance collision. Such collisions may be more frequent in areas where adult $C$. intestinalis can be found in the turbulent wakes of other individuals. Secondly, $C$. intestinalis ova are sometimes released in adhesive mucus strings which rapidly attach to the nearest available substratum (authors' pers. obs.). Fertilisation, development, hatching and settlement of competent larvae can occur within the confines of such mucus strings resulting in abbreviated dispersal and highly aggregated settlement. A final possibility is that such aggregations may be the results of selective post-settlement mortality. Because of improved access to food supplies in the open water column (e.g. Muschenheim 1987), growth and survivorship of individuals adherent to surfaces protruding from the substratum are likely to be greater than for those against the rock wall. Similarly, predation of $C$. intestinalis (by the starfish Asterias rubens; Gulliksen \& Skjævland 1973) may be greater on the rock wall itself than amongst epizoic aggregations.

Two different patterns of aggregation have been observed in ascidians (Svane \& Young 1989): aggregation among individuals of the same age, and selection of adult conspecifics as a settlement site. The present study could be viewed as documenting selection of adults (or their immediate environs) as settlement sites by larvae. However, in contrast to the examples given in Svane \& Young (1989), the response detailed here does not appear to be true gregariousness as defined in the introduction, but is rather aggregation as a result of hydrodynamic processes.

Acknowledgements. We would like to express our thanks to A.-J. Jørgensen for throughtful discussion and laboratory assistance and to the staff of Kristineberg Marine Biological Station for the provision of boat and laboratory facilities. Earlier drafts of this manuscript were substantially improved by comments from J. Dykens, P. Hill, J. R. Pawlik, R. R. Strathmann, and C. M. Young, to whom we are grateful. This study was supported by a Royal Society of London European Exchange Fellowship (to J. Havenhand), the Hierta-Retzius Fund of the Royal Swedish Academy of Sciences, and contract no. B-BU 8526-300 from The Swedish Natural Sciences Research Council (to I. Svane).

\section{LITERATURE CITED}

Berrill, N. J. (1931). Studies in tunicate development. Part II Abbreviation of development in the Molgulidae. Phil. Trans. R. Soc. Ser. B. 219: 281-346

Burke, R. D. (1986). Pheromones and the gregarious settlement of marine invertebrate larvae. Bull. mar. Sci. 39: 323-331

Butman, C. A. (1987). Larval settlement of soft-sediment invertebrates: the spatial scales of pattern explained by active habitat selection and the emerging role of hydrody- 
namical processes. Oceanogr. mar. Biol. A. Rev. 25: 113-165

Clark, P. J., Evans, F. C. (1954). Distance to nearest neighbor as a measure of spatial relationship in populations. Ecology 35: $23-30$

Crisp, D. J. (1974). Factors influencing the settlement of marine invertebrate larvae. In: Grant, P. T., Mackie, A. M. (eds.) Chemoreception in marine organisms. Academic Press, New York, p. 177-265

Denny, M. W. (1988). Biology and the mechanics of the waveswept environment. Princeton Univ. Press., Princeton

Diggle, P. J. (1979). Statistical methods for spatial point patterns in ecology. In: Cormack, R. M., Ord, J. K. (eds.) Spatial and temporal analysis in ecology. International Cooperative Publishing House, Fairland, Maryland, p. 95-150

Dybern, B. I. (1965). The life cycle of Ciona intestinalis (L.) $f$. typica in relation to the environmental temperature. Oikos 16: $109-131$

Eckman, J. E. (1983). Hydrodynamic processes affecting benthic recruitment. Limnol. Oceanogr. 28: 241-257

Eckman, J. E., Nowell, A. R. M., Jumars, P. A. (1981). Sediment destabilisation by animal tubes. J. mar. Res. 39: 361-374

Ertman, S. C., Jumars, P. A. (1988). Effects of bivalve siphonal currents on the settlement of inert particles and larvae. J. mar. Res. 46: 797-813

Grave, C., Nicoll, P. A. (1939). Studies of larval life and metamorphosis in Ascidia nigra and a species of Polyandrocarpa. Publs Carnegie Instn 517: 1-46

Gulliksen, B. , Skjævland, S. H. (1973). The sea-star Asterias rubens L. as a predator on the ascidian Ciona intestinalis (L.) in Borgenfjorden, North Trøndelag, Norway. Sarsia 52: $15-20$

Havenhand, J. N., Svane, I. (1989). Larval behaviour, recruitment, and the rôle of adult attraction in Ascidia mentula O. F. Müller. In: Ryland, J. S., Tyler, P. A. (eds.) Reproduction, genetics and distributions of marine organisms, Proc. 23rd Eur. mar. Biol. Symp. Olsen \& Olsen, Fredensborg, p. $127-132$

Highsmith, R. C. (1982). Induced settlement and metamorphosis of sand dolar (Dendraster exentricus) larvae in predator-free sites: adult sand dollar beds. Ecology 63: 329-337

Keough, M. J., Chernoff, H. (1987). Dispersal and population variation in the bryozoan Bugula neritina. Ecology 68: 199-210

Knight-Jones, E. W. (1953). Laboratory experiments on gregariousness during settling in Balanus balanoides and other barnacles. J, exp. Biol, 30: 584-598

McGee, B. L., Targett, N. M. (1989). Larval habitat selection in Crepidula (L.) and its effect on adult distribution patterns. J. exp. mar. Biol. Ecol. 131: 195-214

Menge, B. A., Sutherland, J. P. (1987). Community regulation: variation in disturbance, competition and predation in relation to environmental stress and recruitment. Am. Nat. 130: 730-757

Millar, R. H. (1953). Ciona. L.M.B.C. Memoirs XXXV, Liverpool University Press, Liverpool

Moore, P. G. (1975). The rôle of habitat selection in determining the local distribution of animals in the sea. Mar, behav. Physiol. 3: 97-100

Muschenheim, D. K. (1987). The dynamics of near-bed seston flux and suspension-feeding benthos. J. mar. Res. 45: 473-496

Pawlik, J. R. (in press). Chemical ecology of the settlement of benthic marine invertebrates. In: Paul, V. J. (ed.) Marine secondary metabolites: their functions in ecological interactions. Cornell Chemical Ecology Series

Roughgarden, J., Gaines, S., Possingham, H. (1988). Recruitment dynamics in complex life-cycles. Science 241: $1460-1466$

Sokal, R. R., Rohlf, F. J. (1981). Biometry. W. H. Freeman \& Co., New York

Svane, I. (1983). Ascidian reproductive patterns related to long-term population dynamics. Sarsia 68: 249-255

Svane, I. (1987). On larval behaviour and post-metamorphic mortality of Ascidia mentula O. F. Müller. Ophelia 27: $87-100$

Svane, I. (1988). Recruitment and development of epibioses on artificial and cleared natural substrata at two sites in Gullmarsfjorden on the Swedish west coast. Ophelia 29: 25-41

Svane, I., Havenhand, J. N., Jørgensen, A.-J. (1987). Effects of tissue extract of adults on metamorphosis in Ascidia mentula O. F. Müller and Ascidiella scabra (O, F. Müller). J. exp. mar. Biol. Ecol. 110: 171-181

Svane, I., Young, C. M. (1989). The ecology and behaviour of ascidian larvae. Oceanogr. mar. Biol. A. Rev. 27: 45-90

Underwood, A. J., Denley, E. J. (1984). Paradigms, explanations and generalization in models for the structure of intertidal communities on rocky shores. In: Strong, D., Simberloff, D., Abele, L. G., Thistle, A. B. (eds.) Ecological communities: conceptual issues and the evidence. Princeton University Press, Princeton, p. 151-180

Vogel, S. (1981). Life in moving fluids. Willard Grant Press, Boston

Yamaguchi, M. (1975). Growth and reproductive cycles of the marine fouling ascidians Ciona intestinalis, Styela plicata, Botrylloides violaceus, and Leptoclinum mitsukurii at Aburatsubo-Moroiso Inlet (central Japan). Mar. Biol. 29: 253-259

Young, C. M. (1988). Ascidian cannibalism correlates with larval behavior and adult distribution. J. exp. mar. Biol. Ecol. 117: 9-26

Young, C. M., Braithwaite, L. F. (1980). Larval behaviour and post-settling morphology in the ascidian Chelyosoma productum Stimpson. J. exp. mar. Biol. Ecol. 42: 157-169

Manuscript first received: August 6, 1990

Revised version accepted: September 3, 1990 